\title{
SOME ASPECTS OF THE FISHERY OF THE THREATENED YELLOW CATFISH HORABAGRUS BRACHYSOMA FROM VEMBANAD LAKE WITH A NOTE ON THEIR LANDINGS AT VAIKOM, KERALA, INDIA
}

\author{
Sreeraj, N. ${ }^{1}$, Rajeev Raghavan ${ }^{1}$ and G. Prasad ${ }^{2}$ \\ ${ }^{1}$ Department of Aquaculture, St. Albert's College, Kochi, Kerala 682018, India; \\ 2 Department of Zoology, University of Kerala, Kariavattom, Thiruvananthapuram, Kerala 695581, India \\ Email: ${ }^{2}$ probios1@hotmail.com (corresponding author)
}

\begin{abstract}
The landings of the endangered bagrid catfish Horabagrus brachysoma from three selected markets along Vembanad Lake, Kerala was quantified at $6744 \mathrm{~kg}$ during October 2003 September 2004, with the greatest share (51\%) from Koluthumkadavu market of Vaikom. A considerable portion of the exploited stock consisted of individuals in the size ranges of $180-280 \mathrm{~mm}$ TL in the case of males and $160-300 \mathrm{~mm}$ TL in the case of females. Seasonal variations in landings have been discussed and an appraisal of the fishing techniques for $H$. brachysoma in the lake ecosystem has been presented.
\end{abstract}

KEYWORDS

Fishing techniques, fishery, Horabagrus brachysoma, landings, Vembanad lake, Yellow Catfish

The Yellow Catfish Horabagrus brachysoma (Gunther) is one of the most important inland food fish, highly appreciated for its taste and having very high consumer demand in the central districts of Kerala, southern India, especially in the regions surrounding the Vembanad lake. In addition, fingerlings of this bright yellow coloured catfish has now become the choice among ornamental fish hobbyists and traders both in India and abroad and there exists an increasing demand for them in the international aquarium markets. As early as the last decade, Kurup et al. (1993) had observed that this species, along with other catfishes of the Vembanad lake were facing serious population declines and that they required immediate protection and artificial propagation. Due to the rapid decrease in populations of this species in the wild, the fish has been listed as Endangered in the Conservation Assessment and Management Plan workshop for assessing the status of freshwater fishes of India (Molur \& Walker, 1998). The commercial significance of H. brachysoma as a much relished food fish and an ornamental species has made it an excellent candidate for commercial aquaculture (Prasad et al., 2005), and preliminary studies on the growth of this species has been studied by Hakim and Prasad (2006). Excepting two general studies, one by Kurup et al. (1995) and the other by CICFRI (2001), no attempts have been made till date to quantify the landings of $H$. brachysoma from the regions around the Vembanad lake, even though the species has been listed as threatened. Our study was a preliminary attempt to quantify the landings of $H$. brachysoma from the regions in and around Vaikom, a major fish landing centre located along the Vembanad lake. Observations were also made with regard to sex and size composition of the specimens as well as seasonal variations in the landings. The fishing techniques for H. brachysoma in the Vembanad lake have also been discussed.

\section{MeTHODOLOGY}

Data on the landings of H. brachysoma from the Vaikom region of Vembanad lake during October 2003-September 2004 were quantified based on the catches registered at three major markets - Koluthumkadavu, Ullala and Kothavara using the data supplied by fish vendors, traders as well as fisherman cooperatives operating in the region. Total landings for each week were compiled by visiting the respondents and gathering the required data. This was then carried out for a year (2003-2004) and the total quantity was arrived at. Information on the fishing techniques for $H$. brachysoma in the lake ecosystem and their mode of operation were collected as a result of direct observations and through structured questionnaires supplied to fishermen involved in the exploitation of the species.

\section{Results}

Estimates of the landings of $H$. brachysoma in the study region during October 2003-September 2004 were around 6,744kg. The share of landings was the greatest from the Koluthumkadavu market of Vaikom $(3,500 \mathrm{~kg})$ followed by Ullala $(2467 \mathrm{~kg})$ and Kothavara $(777 \mathrm{~kg})$. The intensification of fishery during monsoon was evident as the months of June and July alone contributed to more than $50 \%$ of the annual landings of $H$. brachysoma from this region (Fig 1). A smaller yet important second peak in landings was observed during October-November. On the contrary, the market landings of this species from December until May appeared to be very scanty.

A considerable portion of the exploited stock of H. brachysoma in the region consisted of individuals in the size ranges of 180 to $280 \mathrm{~mm}$ TL in the case of males and 160 to $300 \mathrm{~mm}$ TL in females. Landings of both sexes appeared to be in more or less equal numbers during the lean months of fishery (December to May). However, a distinct pattern of sex composition was observed during the peak season of fishery (June-July) when females outnumbered the males by a $3: 1$ ratio.

Catch of H. brachysoma from Vembanad lake were contributed by three major gears - gill nets, cast nets and stake nets. Among the three, the gill net was the predominant gear used for the exploitation of H. brachysoma and was mainly used as set gill net. Both polyamide multifilaments (most cases) and polyamide monofilament (occasionally) are used for the main body of the gill nets. A variety of gill nets could be observed that were used for $H$. brachysoma fishing in Vembanad lake. Among them, the major contributor to the catches of H. brachysoma was the vaisali vala - a common type of bottom set gill net, made of nylon with a 


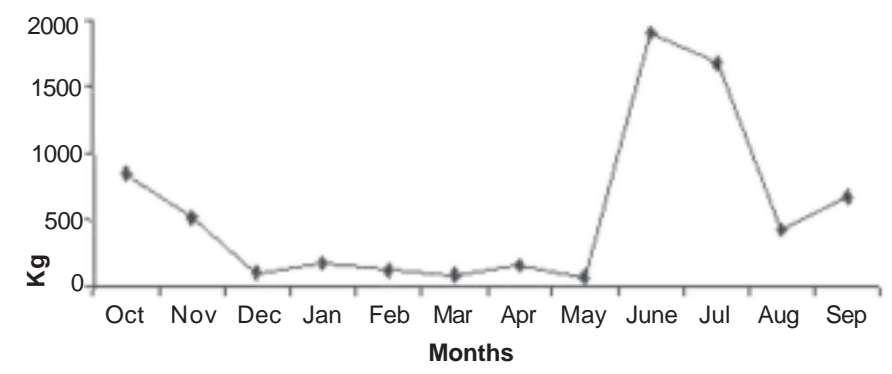

Figure 1. Average month-wise landings of Horabagrus brachysoma from three selected markets in Vaikom region of Vembanad lake during 2003-2004.

plastic head ropes and coir foot ropes. Thermocole, artificial floats and foam rubber materials were used as floats for the gill net. Lead sinkers, large stones and concrete slabs were mainly used as sinkers. The general size of this gillnet was found to be between $400-600 \mathrm{~m}$ in length with a depth of $1-2 \mathrm{~m}$. The mesh size is normally within the ranges of $2-5 \mathrm{~cm}$. In most cases, the gear is operated from plank built canoes in the mid night hours and hauling in the early hours of the day.

Minor contributions in catches also come from cast nets (veesu vala) and stake nets (ooni vala) which are operated in the lake. $H$. brachysoma was also seen to be exploited by the migrant fishermen from the neighbouring state of Karnataka who stay on the banks of the lake for certain months and carry out fishing operations for a variety of inland food fishes using coracles (Vattathoni) (Ramesan \& Ramachandran 2005).

\section{Discussion}

The landing of H. brachysoma at three major markets in Vaikom during 2003-2004 quantified at 6,744kg is on a higher side when compared to the reports of both Kurup et al. (1995) and CICFRI (2001). Kurup et al. (1995) had observed that the landings of $H$. brachysoma in various markets around Vembanad lake were to the tune of $2210.30 \mathrm{~kg}$, whereas CICFRI (2001) had accounted for only $2150 \mathrm{~kg}$. A comparison with the results of Kurup et al. (1995) shows the popularity that $H$. brachysoma has gained as a food fish in the region during the last decade as evident from the higher levels of exploitation. It is also worth mentioning here that the data arising from CICFRI (2001) were those that were obtained during 1996-1997 and was restricted to the markets in the freshwater sector of the lake (southern sector of Vemaband lake).

Of the 51 major and minor markets located in and around the Vembanad lake (Kurup et al., 1995), landings of H. brachysoma was observed in at least 18 (Rajeev, pers. comm.). Additionally, it has also been reported that only $80 \%$ of the total exploited fish stock from the lake ecosystem reaches the various markets and landing centres as the rest are sold locally (Kurup et al., 1995). Taking this system of direct marketing into account and on comparing the earlier datasets (Kurup et al., 1995; CICFRI, 2001), it is to be understood that the total quantity of $H$. brachysoma that may have been actually exploited from the entire lake area would certainly be much higher since the results of the present study was mainly based on landings obtained from three markets of only one region (Vaikom).

Kurup \& Samuel (1985) had described H. brachysoma as an oligohaline species of Vembanad lake which showed a seasonal occurrence during December to May. However, in the present study, it has been observed that $H$. brachysoma occurs throughout the year in Vembanad lake but the bulk of the landings in the major markets are observed only during the monsoon and the immediate post-monsoon months (June- September \& October to December).

Although no data is presently available on the actual stock of the species in the lake, large scale exploitation of this catfish which has been listed as Endangered (Molur \& Walker, 1998), calls for adopting judicious management practices to sustain its future fishery. Of immediate concern would be to bring in appropriate regulations to decrease the intensity of biological overfishing as evidenced by the high female to male ratio of $3: 1$ seen during the peak spawning period in the monsoon months (June-July) and recruitment overfishing during the post-monsoon months (Prasad et al., 2005). The demand for fingerlings of $H$. brachysoma for the international ornamental markets is sure to increase in the near future as also the demand for local consumption. Both market forces will no doubt lead to large scale exploitation of this species leading to a pressure on wild stock.

The National Bureau of Fish Genetic Resources (NBFGR) and the Kerala Agricultural University (KAU) have succeeded in developing a captive breeding technology for this species (Gopalakrishnan et al., 2004). However, efforts should be now undertaken to produce seeds on a mass scale for ranching programmes for aiding in stock enhancement and also for the purpose of initiating culture of this species in small scale farming systems.

\section{REFERENCES}

C.I.C.F.R.I. (2001). Ecology and Fisheries investigations in Vembanad Lake. Central Inland Capture Fisheries Research Institute. Barrackpore. Bulletin 107, $38 \mathrm{p}$

Gopalakrishnan, A. V.S. Basheer, P.M.A. Munner., K.K. Lal., A.G. Ponniah., D. Kapoor, K.G. Padmakumar \& A. Krishnan (2004). Captive breeding of Yellow Catfish, Horabagrus brachysoma, Gunther. In: National Seminar on Responsible Fisheries and Aquaculture. College of Fisheries, Orissa University of Agriculture and Technology, Rangailunda, Orissa. 12-13 February 2004. Abstracts.

Hakim, J. \& G. Prasad (2006). Growth of the Yellow Catfish Horabagrus brachysoma (Gunther) fed with different diets. Zoos' Print Journal 21(1): 2120-2122.

Kurup, B.M. \& C.T. Samuel (1985). Fish and Fishery Resources of Vembanad Lake. In: Harvest and Post-Harvest Technology of Fishes. Proceedings of the Symposium on Harvest and Post-Harvest Technology of Fishes. Society of Fisheries Technologists (India), Kochi. pp77-82

Kurup, B.M., M.J. Sebastian, T.M. Sankaran \& P. Rabindranath(1993). Exploited fishery resources of the Vembanad lake- status of residents and migrants. Fishery Technology special issue. Society of Fishery Technologists. India, 44-49.

Kurup, B.M., M.J. Sebastian, T.M. Sankaran \& P. Rabindranath(1995). Exploited fishery resources of the Vembanad Lake- 4. Estimates of marketable surplus of production. Journal of the Marine Biological Association of India 37(1\&2): 1-10. Molur, S. \& S. Walker (Eds.) (1998). Report of the workshop Conservation Assessment and Management Plan for Freshwater Fishes of India. Zoo Outreach Organisation/ CBSG India, Coimbatore, 156pp.

Prasad, G., R. Raghavan, N. Sreeraj \& P.H.A. Ali (2005). Biology, conservation and culture potential of Horabagrus brachysoma, an endangered bagrid catfish from Vembanad Lake, Kerala, India. In: Sustain Fish 2005 - International symposium on improved sustainability of fish production systems and appropriate technologies for utilization. Cochin University of Science and Technology, Kochi, India. $16^{\text {th }}$ to $18^{\text {th }}$ March 2005. Abstracts.

Ramesan, M.P. \& A. Ramachandran (2005). Vattathoni fishing by the migratory fisherfolk in Kerala. Fishing Chimes 25(2): 42. 